\title{
APARTEMEN, RENTAL OFFICE, DAN MALL DI BOYOLALI DENGAN PENEKANAN PEMECAHAN MASALAH PRIVASI
}

\author{
Hakiem Setyo Bimo \\ Program Studi Arsitektur, Fakultas Teknik, Universitas Tunas Pembangunan Surakarta \\ hakiembimo@gmail.com \\ Eny Krisnawati \\ Program Studi Arsitektur, Fakultas Teknik, Universitas Tunas Pembangunan Surakarta \\ enykrisnawati4@yahoo.com \\ Ismadi \\ Program Studi Arsitektur, Fakultas Teknik, Universitas Tunas Pembangunan Surakarta \\ ismadimt@yahoo.com
}

\begin{abstract}
Abstrak
Berkembangnya potensi industri dan perdagangan di Kabupaten Boyolali, sebagian besar pengusaha diluar kota yang disebut kaum eksekutif berdatangan untuk mengembangkan usahanya di Boyolali. Keberadaan kaum eksekutif tentunya membutuhkan sarana dan prasarana yang sangat dibutuhkan mengingat manusia memiliki kebutuhan hidup seperti kebutuhan primer (sandang, pangan, papan) dan kebutuhan sekunder (berbelanja, rekreasi). Walaupun Kabupaten Boyolali mempunyai beberapa pusat perbelanjaan seperti pasar tradisional maupun swalayan dengan skala kecil, namun dengan meningkatnya jumlah penduduk dan perekonomian yang terus berkembang, sudah saatnya perlu adanya fasilitas perbelanjaan dengan skala besar seperti Mall. Beberapa fasilitas perkantoran di Kabupaten Boyolali walaupun sudah ada namun terbilang masih minim, dengan terus bertambahnya kegiatan perekonomian di Boyolali perlu menambah adanya fasilitas perkantoran sewa guna mendukung perekonomian yang terus berkembang. Adapun kebutuhan rumah tinggal dalam bentuk apartemen juga sangat dibutuhkan dimasa mendatang karena menyadari keterbatasan lahan seiring meningkatnya perkembangan Kabupaten Boyolali. Kebutuhan sarana dan prasarana dengan pola kehidupan masyarakat zaman sekarang yang mengarah kepada kehidupan masyarakat yang serba praktis dan efektif, sehingga mereka sangat menghargai waktu yang disebabkan oleh mekanisme yang serba masal dan mobilitas yang tinggi. Untuk memenuhi kebutuhan tersebut maka perlu adanya ruang untuk mewadahi beberapa fungsi sekaligus dalam satu bangunan. Perancangan bangunan multi fungsi bertujuan untuk menyediakan ruang yang mampu memenuhi kebutuhan-kebutuhan manusia serta memberi kenyamanan bagi pemakainya dalam satu lingkup wilayah yang sama. Adapun konsep arsitektur modern akan diterapkan sebagai konsep pada bangunan multi fungsi tersebut.
\end{abstract}

Kata kunci: Apartemen, Perkantoran Sewa, Mall, Boyolali, Arsitektur Modern.

\begin{abstract}
The growing potential of industry and trade in Boyolali Regency, most entrepreneurs outside the city called executives came to develop their business in Boyolali. The existence of executives certainly requires facilities and infrastructure that are very much needed considering that humans have life necessities such as primary needs (clothing, food, shelter) and secondary needs (shopping, recreation). Although Boyolali Regency has several shopping centers such as traditional markets and small scale supermarkets, but with increasing population and a growing economy, it is time for large scale shopping facilities such as malls. Some office facilities in Boyolali Regency even though they are available but are still minimal, with the continued
\end{abstract}


increase in economic activities in Boyolali, it is necessary to add rental office facilities to support a growing economy. The needs of residential houses in the form of apartments are also very much needed in the future because they are aware of the limitations of land in line with the increasing development of Boyolali Regency. The needs of facilities and infrastructure with the pattern of life of today's society that leads to the life of a completely practical and effective society, so that they greatly value the time caused by a mechanism that is all mass and high mobility. To meet these needs, there is a need for space to accommodate several functions at once in one building. Multifunction building design aims to provide space that is able to meet human needs and provide comfort for the wearer in the same area. The concept of modern architecture will be applied as a concept to the multifunction building.

Keywords: Apartments, Rental Office, Mall, Boyolali, Modern Architecture.

\section{PENDAHULUAN}

\section{A. Latar Belakang}

Kabupaten Boyolali merupakan kabupaten yang berpotensi baik dari segi industri dan perdagangan yang perkembangannya semakin meningkat. Dengan demikian adanya perkembangan Kabupaten Boyolali, maka sebagian besar pengusaha diluar kota atau yang biasa disebut kaum eksekutif berdatangan untuk mengembangkan usahanya di Boyolali. Keberadaan kaum eksekutif di Boyolali, membutuhkan sarana dan prasarana yang sangat dibutuhkan mengingat manusia memiliki kebutuhan hidup seperti kebutuhan primer (sandang, pangan, papan) dan kebutuhan sekunder (berbelanja, rekreasi).

Kabupaten Boyolali juga mempunyai beberapa pusat perbelanjaan seperti pasar tradisional, Luwes, Mitra, dan swalayan-swalayan dengan skala kecil, namun dengan meningkatnya jumlah penduduk dan perekonomian yang terus berkembang, sudah saatnya Boyolali perlu adanya fasilitas perbelanjaan dengan skala besar seperti Mall. Fasilitas perkantoran di Boyolali yang terbilang masih minim, walaupun sudah ada beberapa fasilitas perkantoran namun dengan terus bertambahnya kegiatan perekonomian di Boyolali perlu adanya fasilitas perkantoran sewa guna mendukung perekonomian yang terus berkembang. Adapun kebutuhan rumah tinggal dalam bentuk apartemen juga sangat dibutuhkan dimasa mendatang karena menyadari keterbatasan lahan seiring meningkatnya perkembangan Kabupaten Boyolali.

Kebutuhan sarana dan prasarana dengan pola kehidupan masyarakat zaman sekarang yang mengarah kepada kehidupan masyarakat maju yang serba praktis dan efektif, sehingga mereka sangat menghargai waktu yang disebabkan oleh mekanisme yang serba masal dan mobilitas yang tinggi. Untuk memenuhi kebutuhan tersebut maka perlu adanya ruang untuk mewadahi beberapa fungsi sekaligus dalam satu bangunan. Perancangan mixed-use building bertujuan untuk menyediakan ruang yang mampu memenuhi kebutuhan-kebutuhan manusia serta memberi kenyamanan bagi pemakainya. Bangunan multifungsi atau mixeduse building mengacu pada kombinasi beberapa 
fungsi yang berbeda dalam satu bangunan, misalnya fungsi apartemen, hotel dan mall yang dibangun dalam satu tapak.

Hal mendasar tersebut yang melatar belakangi untuk merencanakan dan merancang Apartemen, Rentall Office, dan Mall yang direncanakan di Boyolali dengan mempertimbangkan lokasi yang dekat dengan daerah Perdangangan, Perkantoran, Pendidikan dan pusat bisnis serta mudah dijangkau oleh transportasi umum maupun transportasi pribadi dengan pendekatan arsitektur modern..

\section{B. Permasalahan}

Bagaimana merencana dan merancang Apartemen, Rental Office dan Mall yang terpadu dengan tingkat privasi yang tinggi untuk masing masing fungsi kegiatan dengan pendekatan arsitektur modern?

\section{METODE PENELITIAN}

Metode yang digunakan dalam hal ini adalah deskriptif analitik sintetis, yaitu proses identifikasi (mendeskripsikan, menguraikan, atau menjelaskan) pada objek yang dipilih sebagai dasar proses analisis dalam penyusunan hasil (analitik) hasil pembahasannya dipadukan (sintetis) sebagai konsep perencanaan dan perancangan wadah kegiatan dimaksud. Kemudian dilakukan pendekatan bentuk, ruang dan fungsi atas dasar pertimbangan berbagai aspek yang berorientasi pada disiplin ilmu arsitektur, landasan teori dan standar yang ada, kemudian diperoleh hasil berupa alternatif pemecahan masalah. Adapun prosesnya berupa,
1. Pengumpulan data, yaitu pengumpulan datadata sekunder untuk bekal survey lapangan guna menghasilkan data primer dan eksplorasi data sekunder melalui literatur dan wawancara.

2. Komplikasi data, yaitu menyusun, memilahmilah dan mengklarifikasikan data kedalam bagian-bagian yang relevan.

3. Analisis data, yaitu pengkajian data dan informasi yang didaptkan dengan pencarian data yang akan digunakan dalam penyusunan konsep perencanaan dan perancangan.

4. Sintetis, yaitu menggabungkan hasil analisis data ke dalam konsep perencanaan dan perancangan Tugas Akhir yang akan dilanjutkan dalam tahap studio Tugas Akhir.

\section{LANDASAN TEORI}

\section{A. Apartemen}

Menurut Marvin Harris, Dictionary of Architecture and Contruction, 1975. Apartemen adalah tempat tinggal (terdiri atas kamar duduk, kamar tidur, kamar mandi, dapur, dan sebagainya) yang berada pada satu lantai bangunan bertingkat yang besar dan mewah, dilengkapi dengan berbagai fasilitas (kolam renang, pusat kebugaran, toko, dan sebagainya).

\section{B. Rental Office}

Menurut Drs. AK.Ramlie R. Mertawijaya, Strategi Pengendalian Administratif Perusahaan. Rental Office/ Kantor sewa adalah wadah yang digunakan untuk menampung kegiatan manusia secara berkelompok, dengan sifatnya yang administratif serta melembaga dalam satu 
bentuk usaha yang komersial, dengan cara menyewakan lantai atau ruang kepada pihak yang memerlukan demi kelancaran usaha dalam mencapai tujuan

\section{Mall}

Dalam buku Community Builders Handbook, 1977. Mall/ Pusat perbelanjaan adalah sebuah tempat kegiatan pertukaran dan distribusi barang atau jasa yang bercirikan komersial. Pusat perbelanjaan adalah sekelompok kesatuan. bangunan komersial yang dibangun dan didirikan pada sebuah lokasi yang direncanakan. dikembangkan, dimulai dan diatur menjadi kesatuan operasi (operating unit), berhubungan dengan Iokasi, ukuran tipe toko dan area perbelanjaan dari unit tersebut. Unit ini juga menyediakan parkir yang dibuat berhubungan dengan tipe dan ukuran total dari toko-toko.

Adapun menurut Dewan Pusat Perbelanjaan Internasional, 1999. Mall adalah pusat perbelanjaan yang secara arsitektur dengan arsitektur yang tertutup dengan suhu yang diatur dan memiliki jalur untuk berjalan-jalan teratur sehingga berada diantara toko-toko yang saling berhadapan. Karena bentuk arsitekturnya yang meluas/ melebar, umumnya bangunan mall memiliki tidak lebih dari 3 lantai. Didalam Mall penyewa besar (Anchor Tenant) lebih dari satu penyewa/ banyak.

\section{Arsitektur Modern}

Arsitektur Modern adalah suatu istilah yang diberikan kepada sejumlah bangunan dengan gaya karakteristik yang mengutamakan kesederhanaan bentuk dan menghapus segala macam ornamen.

Menurut Rayner Banham pada bukunya yang berjudul "Age of The Master: A Personal View of Modern Architecture”, 1978, perkembanagan arsitektur modern menekankan pada kesederhanaan suatu desain. Arsitektur modern merupakan Internasional Style yang menganut Form Follows Function (bentuk mengikuti fungsi). Bentukan platonic solid yang serba kotak, tak berdekorasi dan perulangan yang monoton merupakan ciri arsitektur modern.

\section{ANALISIS DAN HASIL}

\section{A. Analisis Tapak}

\section{a. Tapak}

Dasar pertimbangan kriteria penilaian lokasi sebagai berikut.

1. Kemudahan Pencapaian

2. Letak Strategis

3. Kepadatan aktivitas

4. Privasi

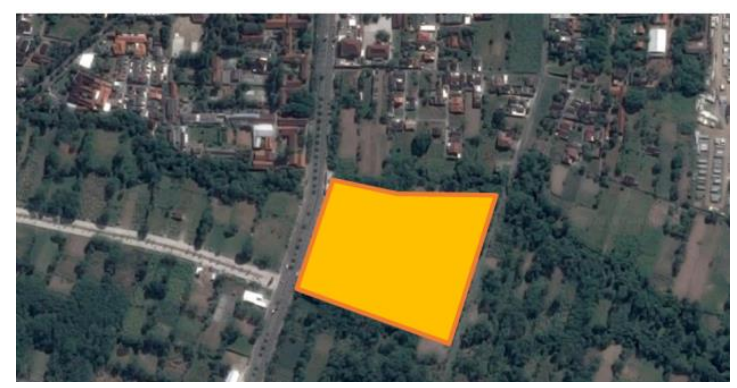

Gambar. 1. Lokasi Tapak 


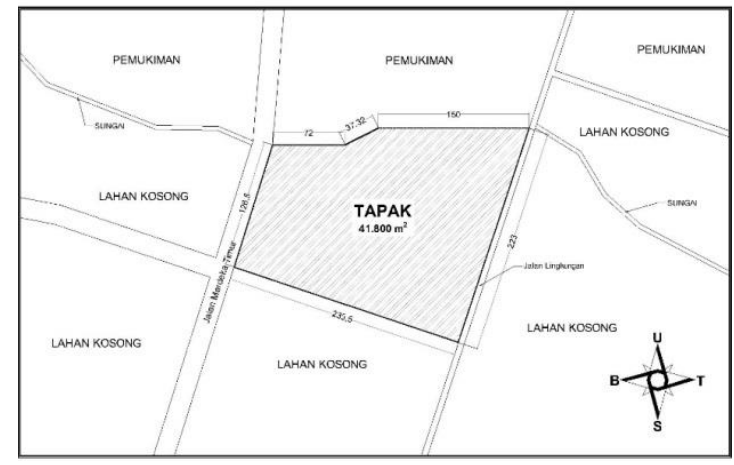

Gambar. 2. Data Tapak

Dengan keterangan sebagai berikut:

1. Terletak di sebelah Timur Jalan Merdeka Timur, kec. Mojosongo, Kab. Boyolali.

2. Lahan kosong/ perkebunan

3. Luas Lahan $+41.800 \mathrm{~m}^{2}$

4. Terletak dekat dengan ikon alun-alun kidul kota Boyolali

5. Akses yang mudah dicapai, tidak jauh dari Jalan Raya Semarang-Solo

\section{b. Pencapaian}

Dasar pertimbangan yang diperlukan dalam pencapaian untuk menentukan ME dan SE, adalah sebagai berikut.

1. Arah datangnya pengunjung baik yang memakai kendaraan maupun yang berjalan kaki.

2. Tata letak yang memiliki tingkat kelancaran dan keamanan lalu lintas dan mempertimbangkan terhadap persimpangan atau crossing (lalu lintas lancar dan aman) baik akses masuk maupun keluar bagi pengunjung.

3. Privasi bagi para penggunanya.

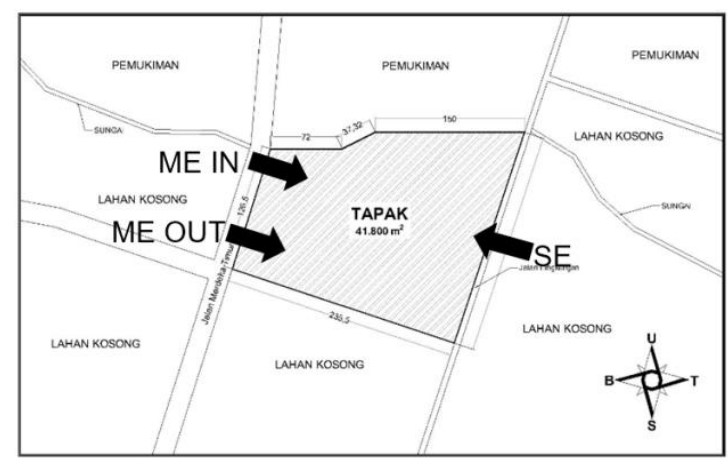

Gambar. 3. Pencapaian Tapak

\section{c. Orientasi}

.Dengan dasar pertimbangan pengenalan bangunan sebagai berikut.

1. Menonjolkan pengenalan bangunan

2. Diorientasikan kearah yang paling banyak terlihat oleh pengamat

3. Mengarahkan pengunjung menuju enterance bangunan secara efektif (cepat, mudah, lancar).

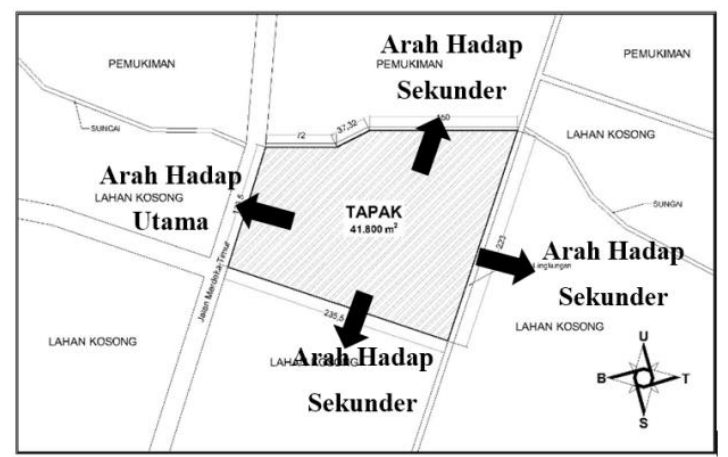

Gambar. 4. Orientasi Bangunan

\section{d. Titik Tangkap}

Dasar pertimbangan titik tangkap sebagai berikut.

1. Titik tangkap tertinggi di ambil dari intensitas penggunaan dan pengguna jalan terbanyak.

2. Area titik tangkap terbesar dimanfaatkan untuk penempatan point of interst bangunan dan pengenalan terhadap fungsi bangunan.

3. Besarnya sudut padang 
- Pejalan kaki 60 pandangan saat lurus ke depan

- Kendaraan roda dua 45 kecepatan $40 \mathrm{~km} / \mathrm{jam}$

- Kendaraan roda empat 30 kecepatan $40 \mathrm{~km} / \mathrm{jam}$

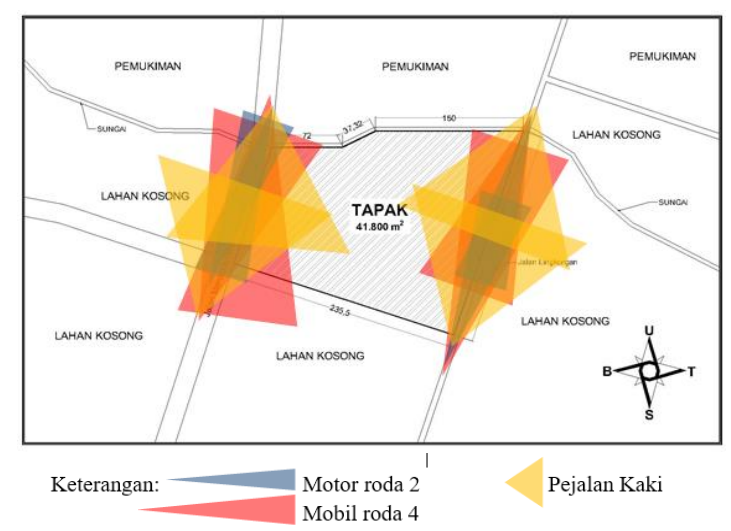

Gambar. 5. Analisis Titik Tangkap

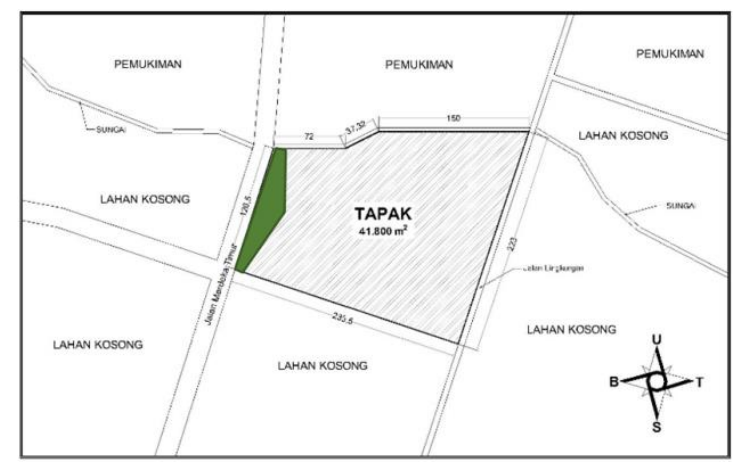

Gambar. 6. Hasil Orientasi Bangunan

\section{e. Kebisingan}

Dasar pertimbangan kebisingan adalah sebagai berikut.

1. Intensitas sumber bising

2. Lalu lintas merupakan sumber kebisingan tertinggi

3. Antisipasi kebisingan

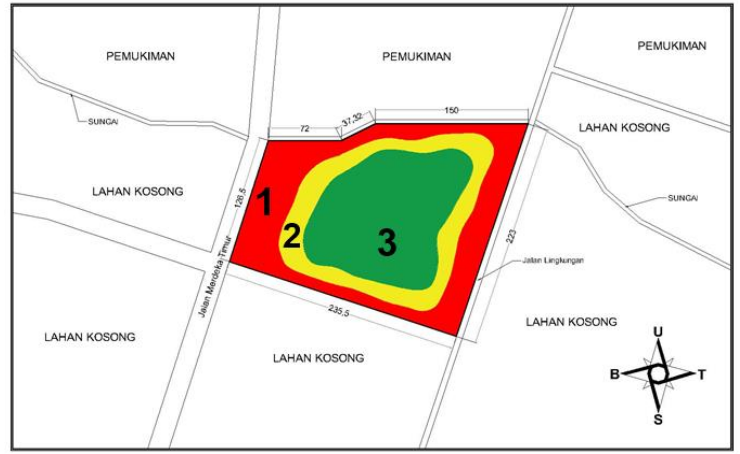

Gambar. 7. Hasil Analisis Kebisingan

\section{Keterangan:}

1. Angka 1 yaitu zona dengan tingkat kebisingan tinggi, digunakan untuk ruangruang dengan tingkat kebisingan tinggi, contoh tempat parkir.

2. Angka 2 yaitu zona dengan tingkat kebisingan sedang, digunakan untuk ruangruang dengan kebisingan sedang. Contoh ruang display.

3. Angka 3 yaitu zona dengan kebisingan rendah, digunakan untuk ruang-ruang dengan kebisingan rendah, contoh mushola

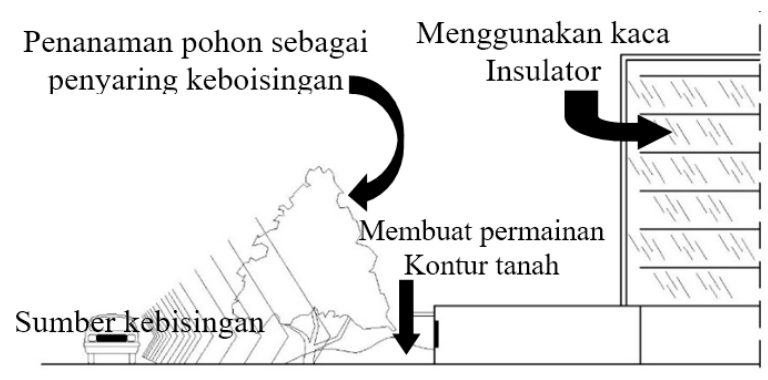

Gambar. 8. Hasil Antisipasi Kebisingan

\section{f. Hujan}

Dasar pertimbangan untuk antisipasi terhadap hujan sebagai berikut.

1. Antisipasi terhadap air hujan yang masuk kedalam bangunan

2. Antisipasi genangan air hujan dengan pemanfaatan vegetasi untuk penyerapan air dan pengikat tanah 


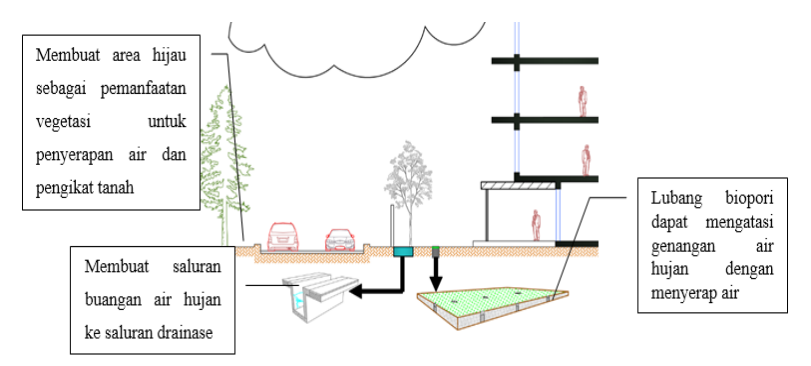

Gambar. 9. Hasil Antisipasi Terhadap Hujan

Berdasarkan dasar pertimbangan diatas, maka antisipasi untuk mengatasi masalah hujan yaitu.

1. Membuat saluran buangan air hujan ke saluran drainase

2. Membuat area hijau sebagai pemanfaatan vegetasi untuk penyerapan air dan pengikat tanah

3. Membuat lubang biopori

\section{g. Angin}

Dasar pertimbangan pengantisipasian terhadap arah datangnya angin:

1. Arah angin

2. Pergerakan angin

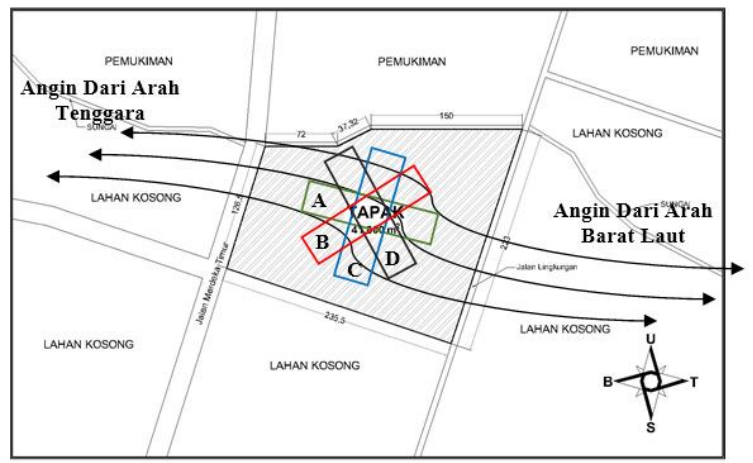

Gambar. 10. Analisa Terhadap Angin

Lay out massa bangunan yang dipilih berdasarkan analisa adalah massa A, karena posisi massa bangunan yang mendukung orientasi bangunan dan masih bisa mendapatkan penanganan.

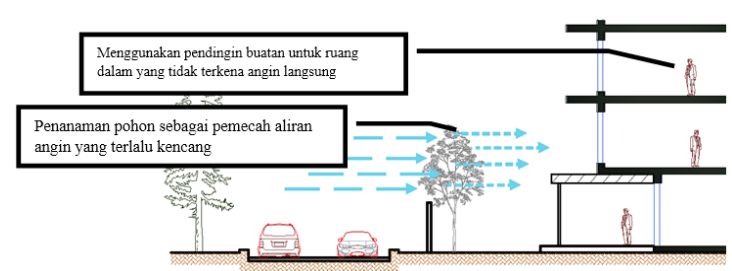

Gambar. 11. Hasil Antisipasi Terhadap Angin

Adapun antisipasi untuk mengatasi masalah angin yaitu.

1. Membuat penanaman pohon agar memecah dan meminimalisir angin kencang.

2. Menggunakan pendingin buatan untuk ruang dalam yang tidak terkena angin langsung.

\section{h. Matahari}

Dengan dasar pertimbangan analisis orientasi terhadap matahari sebagai berikut.

1. Memanfaatkan sinar matahari yang tidak langsung / sinar pantul agar tidak menyilaukan

2. Menghindari sinar matahari yang berlebihan

3. Memanfaatkan sinar matahari yang cukup untuk bangunan

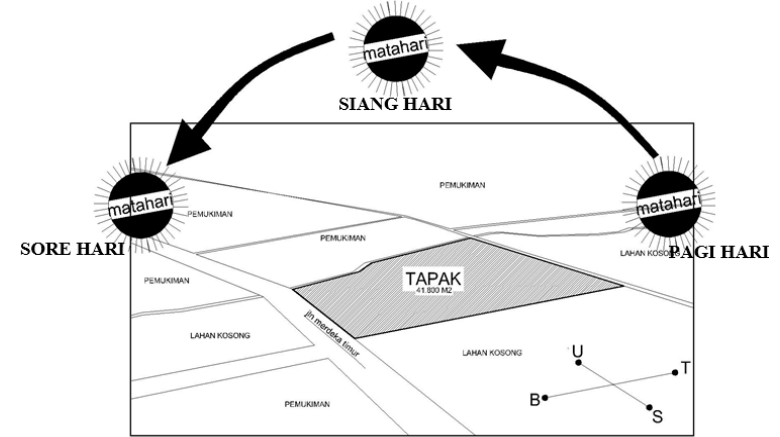

Gambar. 12. Analisa Terhadap Matahari

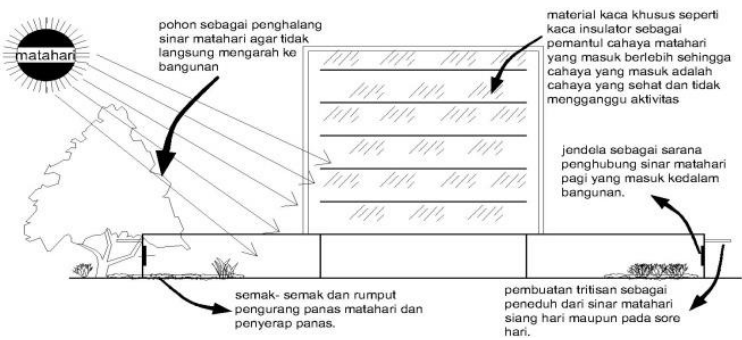

Gambar. 13. Hasil Antisipasi Terhadap Matahari 
Untuk mengatasi cahaya matahari yang berlebih maka yang dilakukan adalah:

1. Meletakkan vegetasi di area tapak dan diharapkan dapat memfilter/ mengurangi intensitas cahaya yang masuk secara langsung pada bangunan

2. Membuat permainan kontur tanah di sekitar tapak.

3. Pemakaian kaca insulator sebagai pemantul cahaya berlebih dari matahari sehingga tidak mengganggu aktivitas dalam bangunan

\section{B. Besaran Ruang}

Tabel 1. Besaran Ruang

\begin{tabular}{|l|c|}
\hline Kelompok Kegiatan & Besaran Ruang \\
\hline Apartemen & $32.325 \mathrm{~m}^{2}$ \\
\hline Rental Office & $22.321 \mathrm{~m}^{2}$ \\
\hline Mall & $34.127 \mathrm{~m}^{2}$ \\
\hline Servis & $311 \mathrm{~m}^{2}$ \\
\hline Total & $89.084 \mathrm{~m}^{2}$ \\
\hline
\end{tabular}

"KDB Keseluruhan Tapak : :60\% dari Total Luas Tapak : $60 \% \times 41.800 \mathrm{~m}^{2}$

$: \underline{\mathbf{2 5 . 0 8 0} \mathbf{~ m}^{2}}$

*KDH Keseluruhan Tapak : :40\% dari Total Luas Tapak : $40 \%$ x $41.800 \mathrm{~m}^{2}$

$: \underline{16.720 \mathrm{~m}^{2}}$

Perhitungan Luas Dasar Bagunan

a. KDB Mall $=40 \%$ dari KDB Keseluruhan Tapak $=40 \% \times 25.080 \mathrm{~m}^{2}=\underline{10.032 \mathrm{~m}^{2}}$

b. KDB Rental Office $\quad=10 \%$ dari KDB Keseluruhan Tapak $=10 \% \times 25.080 \mathrm{~m}^{2}=\underline{2.508 \mathrm{~m}^{2}}$

c. KDB Apartemen $\quad=10 \%$ dari KDB Keseluruhan Tapak $=10 \% \times 25.080 \mathrm{~m}^{2}=2.508 \mathrm{~m}^{2}$

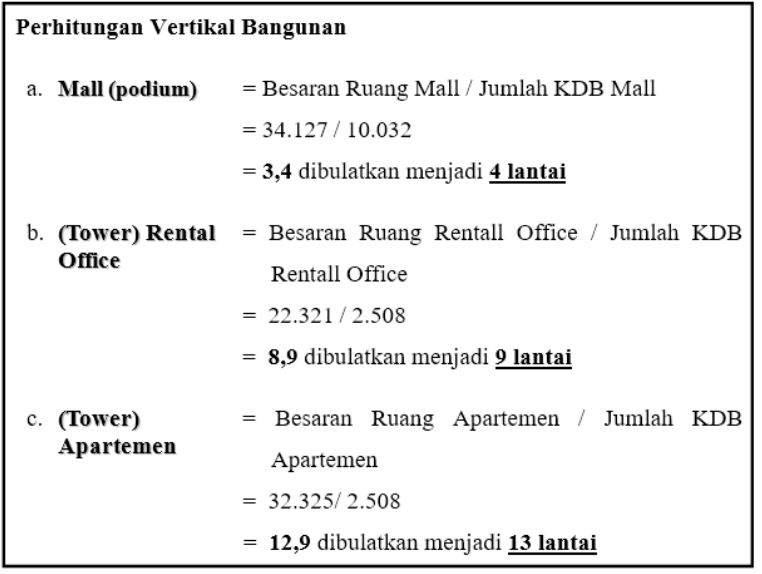

C. Zonning

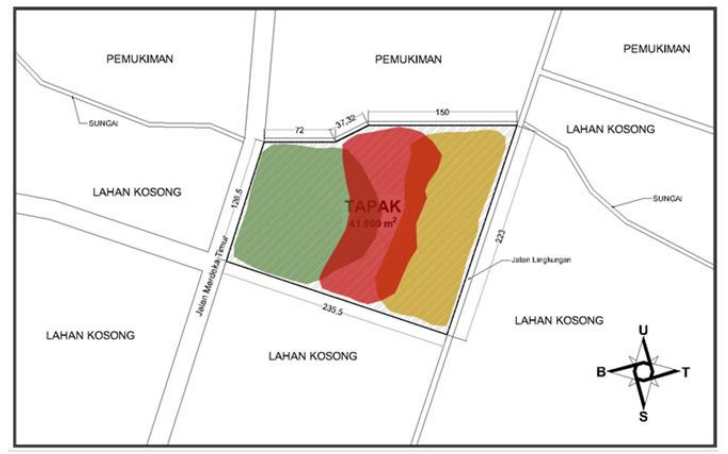

Gambar. 14. Zonning Horizontal

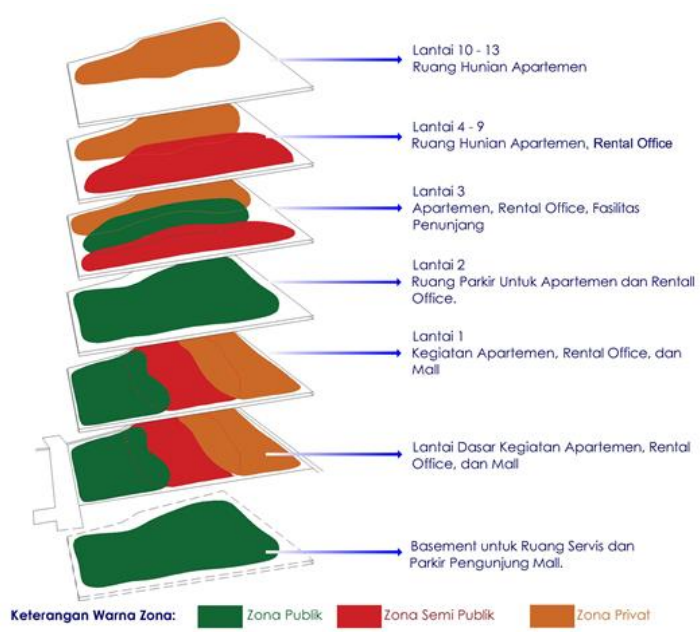

Gambar. 15. Zonning Vertikal

\section{Hasil Desain}

Dari hasil analisis, hasil besaran ruang, serta perzonningan, maka disusunlah suatu rancangan yang menghasilkan suatu desain guna menyelesaikan permasalahan yang dipersoalkan. 


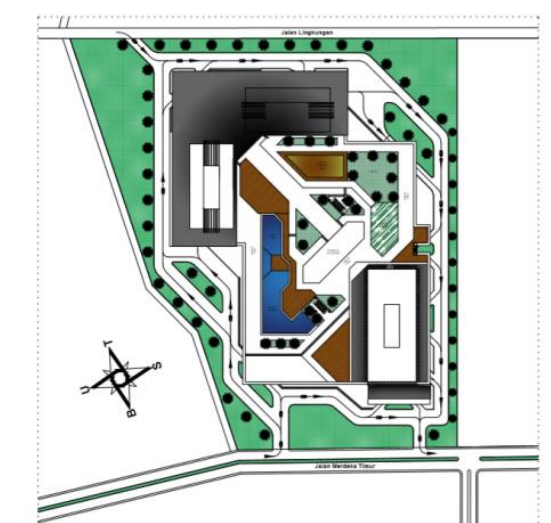

Gambar. 16. Site Plan

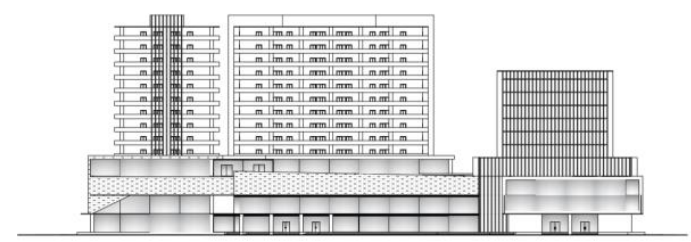

Gambar. 17. Tampak Barat

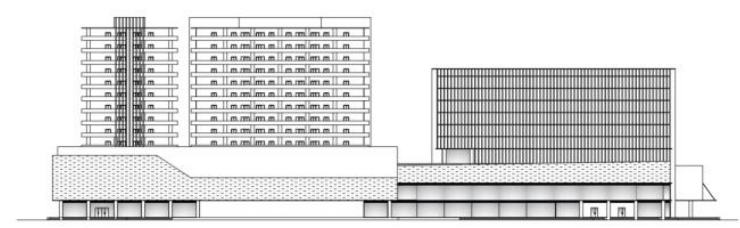

Gambar. 18. Tampak Utara

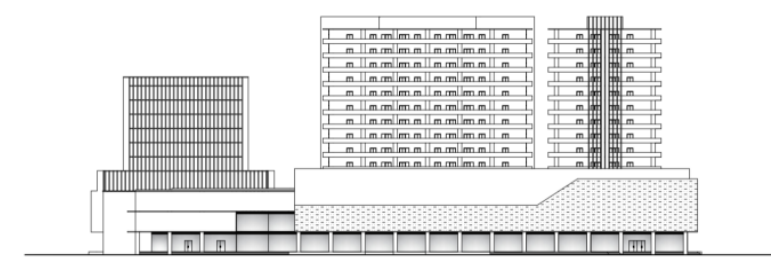

Gambar. 19. Tampak Timur

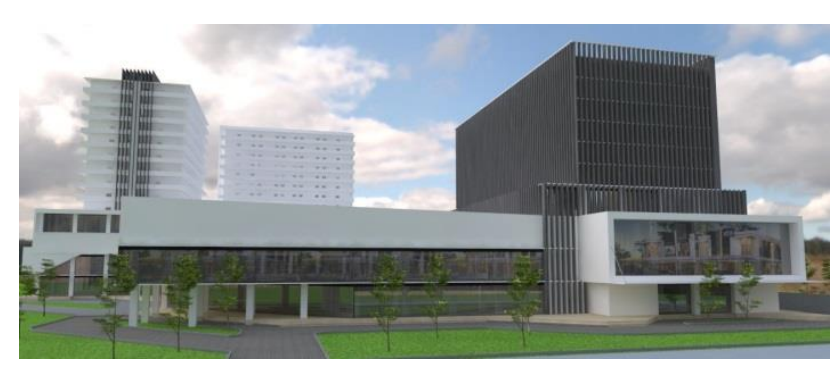

Gambar. 20. Desain Final view 1

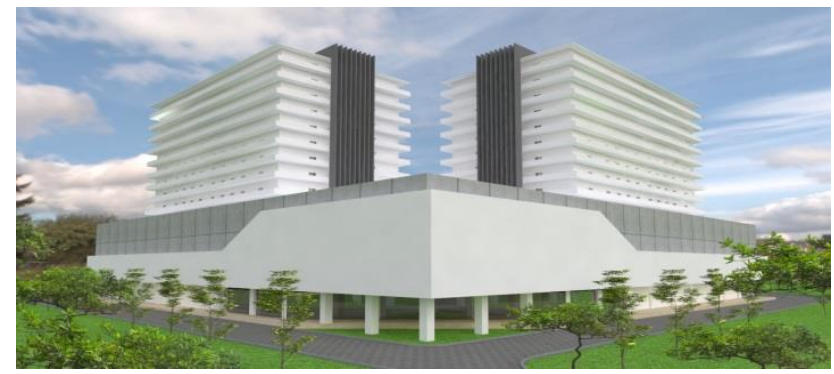

Gambar. 21. Desain Final view 2

\section{KESIMPULAN/RINGKASAN}

Berdasarkan analisis perencanaan melalui survey, wawancara, dan literatur dihasilkan rancangan Apartemen, Rental Office,dan Mall di Boyolali dengan penekanan pemecahan masalah privasi dan dengan berpendekatan arsitektur modern.

\section{UCAPAN TERIMA KASIH}

Dengan memanjatkan puji syukur ke hadirat Tuhan Yang Maha Esa, atas segala rakhmat dan karunianya-Nya sehingga penulis dapat menyelesaikan Tugas Akhir. Maka pada kesempatan ini penulis mengucapkan terima kasih kepada pihak-pihak sebagai berikut.

1. Kepada Ibu Ir. Eny Krisnawati, M.Si., selaku Dekan Fakultas Teknik Universitas Tunas Pembangunan Surakarta dan selaku Dosen Pembimbing Utama

2. Kepada Bapak Ir. Ismadi, MT., selaku Dosen Pembimbing Pembantu

3. Kepada Bapak A. Bamban Yuuwono ST., MT, selaku Ketua Progdi Arsitektur Fakultas Teknik Universitas Tunas Pembangunan Surakarta

4. Kepada Bapak Ir. Indro Sulistyanto, MT. selaku dosen Penguji 1

5. Kepada Ibu Ir. Danarti Karsono, MT. selaku dosen Penguji 2

6. Orang tua dan keluarga yang memberikan dukungan baik secara moral dan materi kepada penulis menjalankan tugas-tugas telah diberikan.

7. Semua pihak yang tidak dapat disebutkan satu per satu, yang telah ikut membantu 
secara langsung maupun tidak langsung

\section{DAFTAR PUSTAKA}

Akmal Imelda, (2007). Menata Apartemen, Jakarta: PT. Gramedia Pustaka Utama

Amril Sjamsul, (2002). Data Arsitektur Jilid 2. Jakarta: Erlangga

Baedhowi, Idrus (2018): Mall, Rental Office, Dan Apartemen Di Boyolali Berpendekatan Arsitektur Organik, Surakarta: Tugas Akhir Program Studi Arsitektur Fakultas Teknik Universitas Tunas Pembangunan Surakarta.

Dewan Pusat Perbelanjaan Internasional, 1999

Endy, Marlina, 2008, Perancangan Bangunan Komersial. Yogyakarta: ANDI

Fleming, Honour dan Pevsner, 1999, Penguin Dictionary of Architecture. Penguin

Joseph De Chiara, (2001) Time Saver Standards for Building Type. United States of America: Mc Graw Hill Book Company

Karyono, T. H. (2016). Arsitektur Tropis: Bentuk, Teknologi, Kenyamanan, \& Penggunaan Energi. Jakarta: Erlangga.

Marvin Harris (1975). Dictionary of Architecture and Contruction. United States of America: Mc Graw Hill Book Company

Mulyadi, F. P. (2012). Proses Perancangan Taman Vertikal Singapore Air Traffic Control (SATC) (Kegiatan Magang di Grenology Pte. Ltd., Singapura). Institut Pertanian Bogor, 1-105.

Neufert, E. (1996). Data Arsitek Edisi 33 Jilid 1. Jakarta: Erlangga

Noor Cholis Idham. 2018. Earthquake Failures on Buildings and The Role of Architect on Building Safety. Architecture Department, Universitas Islam Indonesia.

Pusat Bahasa Depdiknas (2016). Kamus Besar Bahasa Indonesia Edisi kelima, Jakarta: Balai Pustaka

RTRW Kabupaten Boyolali tahun 2011-2031

Rubenstein Harvey M. (1978). Central City Malls. Michigan: John Wiley \& Sons

Suputra, I. U. (2015). Bangunan Multi Fungsi (Mixed-Use Building) Fasilitas Hotel Resort dan Mall di Lovina, Buleleng. Universitas Udayana, 1-166.
Wibi Hardani, Earnest Neufert, (2002). Data Arsitek Jakarta: Erlangga.

Yashinsky, M. (2006). Earthquake damage to structures. In W. Chen \& E. Lui (Eds.), Earthquake engineering for structural design (p. 1-58.). Boca Raton: Talyor \& Francis.

Yanuari Mudiarjo, (2008). Apartemen di Surakarta. Tugas Akhir Jurusan Teknik Arsitektur Fakultas Teknik Universitas Muhammadiyah Surakarta 